\title{
CDW PHOTOGRAMMETRY OF LOW RELIEF FLUVIAL FEATURES: ACCURACY AND IMPLICATIONS FOR REACH-SCALE SEDIMENT BUDGETING
}

\author{
G. L. HERITAGE ${ }^{1 *}$, I. C. FULLER ${ }^{2}$, M. E. CHARLTON ${ }^{3}$, P. A. BREWER ${ }^{4}$ AND D. P. PASSMORE ${ }^{3}$ \\ ${ }^{1}$ Department of Geography, University of Salford, Manchester, M5 4WT, UK \\ ${ }^{2}$ Division of Geography and Environment Management, Lipman Building, University of Northumbria at Newcastle, Newcastle upon Tyne, \\ NE1 8ST, UK \\ ${ }^{3}$ Department of Geography, University of Newcastle, Newcastle upon Tyne, NE1 7RU, UK \\ ${ }^{4}$ Institute of Geography and Earth Sciences, University of Wales, Aberystwyth, Ceredigion, SY23 3DB, UK
}

Received 3 March 1998; Revised 21 March 1998; Accepted 30 April 1998

\begin{abstract}
Terrestrial photogrammetry enables rapid survey to be undertaken in the fluvial environment, a crucial factor when assessing highly dynamic features. In addition, it permits the generation of terrain surfaces at a level of detail which, given equal time constraints in the field, far exceeds the detail permitted by conventional tacheometric survey. This study details the levels of accuracy that can be achieved using the RolleiMetric Close-range Digital Workstation (CDW) photogrammetric survey technique on a variety of low relief fluvial geomorphic features (lateral, point and mid-channel bars) ranging from $10 \mathrm{~m}^{2}$ to $100 \mathrm{~m}^{2}$. The CDW software processes image data from an array of photographs and establishes a set of three-dimensional co-ordinates for the photographed object. The accuracies achieved across all bar surfaces were well within the resolution defined by the maximum size of the gravel on the bar surface (mean errors were between 0.026 and $0.057 \mathrm{~m}$ ). The use of CDW photogrammetry does not require experienced personnel; however, care must be taken during the survey to minimize edge effects and to ensure that target density is sufficient to produce a terrain model that is accurate to within the limits of the surface sediment size. Guidance on target density as a function of terrain roughness is given to aid the user. A methodology is suggested that will allow CDW to be incorporated into sediment budgeting techniques, improving the level of achievable accuracy. (C) 1998 John Wiley \& Sons, Ltd.
\end{abstract}

KEY WORDS: photogrammetry; sediment budgeting; surveying; bars

\section{INTRODUCTION}

Research designed to evaluate the magnitude of change in fluvial environments has traditionally employed one, or a combination, of three field techniques. First, in situ measuring devices such as erosion pins and scour chains can provide detail at a spatial level defined by the density of the measurement network (Lawler, 1992). Although often providing high resolution data on bank erosion, the technique does not easily permit channel bed erosion to be monitored. Second, cross-section resurvey can generate data on erosion and deposition at 'a point' over time (Martin and Church, 1995). However, the accuracy of this technique in evaluating reach-scale sediment budgets is limited because it does not account for scour and fill occurring between surveyed profiles. Finally, field surveys of channel planform can provide detailed two-dimensional data of channel positions and depositional features. Conducting repeat surveys enables bank and bar sediment fluxes to be established (Goff and Ashmore, 1994). Planform surveys have also been augmented with photogrammetric techniques, where data from digitized stereo photographs are processed within a geographic information system package. Although high levels of accuracy are achievable, data processing is often time-consuming and requires specialist skills.

The value of photogrammetry in geomorphology is already well established (Lane et al., 1993, 1994; Barker et al., 1997). Terrestrial photogrammetry enables rapid survey to be undertaken in the field, which may be important when assessing highly dynamic features (Lane et al., 1994). In addition, it permits the generation of

\footnotetext{
* Correspondence to: Dr G. Heritage, Department of Geography, Peel Building, University of Salford, Manchester, M5 4WT, UK 
digital terrain models at a level of detail which, given equal time constraints in the field, far exceeds the detail permitted by conventional tacheometric survey (Barker et al., 1997).

Applications and associated levels of accuracy have varied: Wicken and Barton (1971) monitored rock slope displacement to an accuracy level of $\pm 0.00015 \mathrm{~m}$; Kirby (1991) measured desert microrelief down to 0.001 m; and Barker et al. (1997) determined the relief of a river cliff on the River Yarty, Devon, to an accuracy of $\pm 0.03 \mathrm{~m}$. This study details the levels of accuracy that can be achieved by photogrammetry using the RolleiMetric Close-range Digital Workstation (CDW) on a variety of low relief fluvial geomorphic features (lateral, point and mid-channel bars) ranging from $10 \mathrm{~m}^{2}$ to $100 \mathrm{~m}^{2}$. Guidelines are provided on field technique designed to minimize errors in the mapping of a terrain surface and to determine the necessary minimum target density for a given level of accuracy. The technique may then be incorporated into a revised methodology for sediment budgeting to provide a more accurate estimate of sediment flux rates that can be estimated on an event basis following repeat photogrammetry.

\section{PHOTOGRAMMETRIC SURVEY TECHNIQUE}

\section{Photography}

The RolleiMetric CDW represents a new approach to terrestrial photogrammetric survey. The CDW software processes image data from an array of photographs and establishes a set of three-dimensional coordinates for the photographed object. Photography is carried out using a metric camera (in this study a Rollei 35 Classic); the precise calibration details of the camera, and the Réseau number used, are input to the CDW software. CDW accounts for lens distortions in the generation of co-ordinates, and is capable of making allowances for focal length, co-ordinates of principal image point, parameters of radial-symmetric distortion, tangential and radial-asymmetric distortion and allowance of affinity and shear of the image co-ordinate system (Rollei User Manual, 1996). The CDW software runs under Windows 95 on a PC and the output can be an ASCII file (x, y, z co-ordinates) or an AutoCAD DXF file (readable by a wide variety of mapping packages).

$\mathrm{CDW}$ requires an array of three to six photographs taken from different positions (camera stations) around the object; there is no need to establish any element of stereoscopy between them, and thus no regular overlap is required. However, precision in subsequent co-ordinate generation is enhanced by taking the photographs at as obtuse an angle as possible, both in terms of height and plan, as the latter favours clear and precise intersection of epipolar lines used in the system orientation and co-ordinate generation in CDW described below. In this study, photography was acquired by standing on top of a $3 \mathrm{~m}$ stepladder and greatest accuracies were obtained where the camera to target angle was maintained above $30^{\circ}$.

To ensure precision in the identification of common points between photographs, thus avoiding difficulties in identifying the same gravel clast from different photographs of the surveyed gravel bars (attributed as a source of error by Lane et al., 1994), a grid of $15 \times 15 \mathrm{~cm}$ survey targets was placed across the surface of the feature of interest, in this case gravel-bar surfaces (Figure 1). These targets were placed at regular intervals but particularly along breaks in slope to ensure a high level of topographical detail in subsequent digital terrain models (DTMs). For the CDW software to establish a three-dimensional co-ordinate for a given survey target on the bar surface, the target must be visible in two (three for 'system fixing', see below) adjacent photographs. The more photographs in which the common points are visible, the higher the degree of co-ordinate precision, thus improving the accuracy of the DTM. Once the photographic film had been processed, the photographs were scanned in black and white at a minimum resolution of $300 \mathrm{dpi}$, and imported into the CDW software in Windows Bitmap (*.bmp) format. Common points (survey targets) in the photographs were digitized to generate the three-dimensional co-ordinates.

\section{CDW analysis}

To generate three-dimensional co-ordinates for utilization in a DTM, CDW requires a series of orientation points across the photographed feature (a minimum of three for the entire feature). Each orientation point is assigned an $\mathrm{x}, \mathrm{y}$ and $\mathrm{z}$ co-ordinate, either on an arbitrary basis, or defined by tacheometric survey (as in this 
study). These orientation points define the local object co-ordinate system, the scale for which is provided by distance measurements taken between these points, derived either from the tacheometric survey used to generate the co-ordinates or from measurement by tape.

Having defined the co-ordinate system in the CDW software, the approximate position of each camera station requires definition in order to give initial relative orientations for the photos. This is achieved by determining the camera stations by graphical interaction on-screen in CDW; in addition, the approximate height and cameral angle is required. A photo co-ordinate system is then established by digitizing on-screen the Réseau crosses on each photograph. By reverting the measured Réseau cross positions back to the Réseau number identified when defining camera data (see above), CDW minimizes distortion errors, which may have arisen during the photography, film development or scanning. Computation of the Réseau transformation identifies the extent of any distortion; generally, transformation errors are less than $0.03 \mathrm{~mm}$ (Rollei User Manual, 1996).

Approximately 10 image points (survey targets) are then digitized on-screen in each photograph for subsequent system fixing and multi-photo orientation, with at least five being common between adjacent photographs. These image points should be distributed over the whole image format and be measured in at least three images that were taken from different camera stations. Using multi-photo orientation, the photos are correctly orientated, one by one, and the co-ordinate system fixed; this recovers the photographic situation of a photo assembly (i.e. determines camera stations) and computes three-dimensional co-ordinates for the image points (targets) measured. This is achieved on the basis of the camera data (calibration values and approximate positioning), photo co-ordinates, definition of the object co-ordinates for orientation points and the 10 digitized common points in adjacent photographs. The sequence in which the photographs are to be computed requires definition, as successive images must have at least five points in common in order for the system to be fixed and the photo sequence orientated.

Computation of the three-dimensional co-ordinates is done automatically in the software on a step-by-step basis, as described in the User Manual.

1. Multi-photo orientation in the model: computation of camera stations and object points in a local co-ordinate system that is defined by the first two camera stations. This undertakes computation of: (i) a relative orientation of the first image pair; (ii) the camera stations of the third to the $n$th image by spatial resection; and (iii) further object points by intersection.

2. System transformation: transformation of the object points into the defined co-ordinate system, i.e. system fixing.

3. Multi-photo orientation in the specified co-ordinate system: computation of all camera stations by spatial resection and computation of improved image point co-ordinates by intersection.

Residuals, which are the deviations between a measured point co-ordinate and a point co-ordinate that has been computed from the determined object point, are displayed in the software and allow an assessment of accuracy of the generated co-ordinates. Residuals are generally less than $0.1 \mathrm{~mm}$, although higher values may be acceptable when measuring a coarse gravel surface. In more advanced versions of the CDW software, bundle adjustment is also possible; however, the Basic version used here does not allow such computation.

Three-dimensional co-ordinates are established within both the orientated and fixed images for additional points which will add detail to any subsequent DTM, but which are not required for multi-photo orientation (the Basic version of CDW will only accept a maximum of 128 image points). The co-ordinates for these points are calculated by digitizing image points which are common to at least two photos, from which intersection is undertaken automatically in a three-dimensional measuring program (Rollei User Manual, 1996) run within CDW. These measurements are supported by epipolar lines, shown on-screen by the software, as a point that has been measured in one photo can theoretically only be situated on a straight line in another photo (as the system has been fixed and the photos orientated). At this stage, each digitized point need only be visible in two adjacent photographs, although identification in a third is facilitated by the intersection of the epipolar lines generated from the previous two photos. The co-ordinates produced within CDW can then be transferred into any form of software capable of generating and analysing DTMs. 

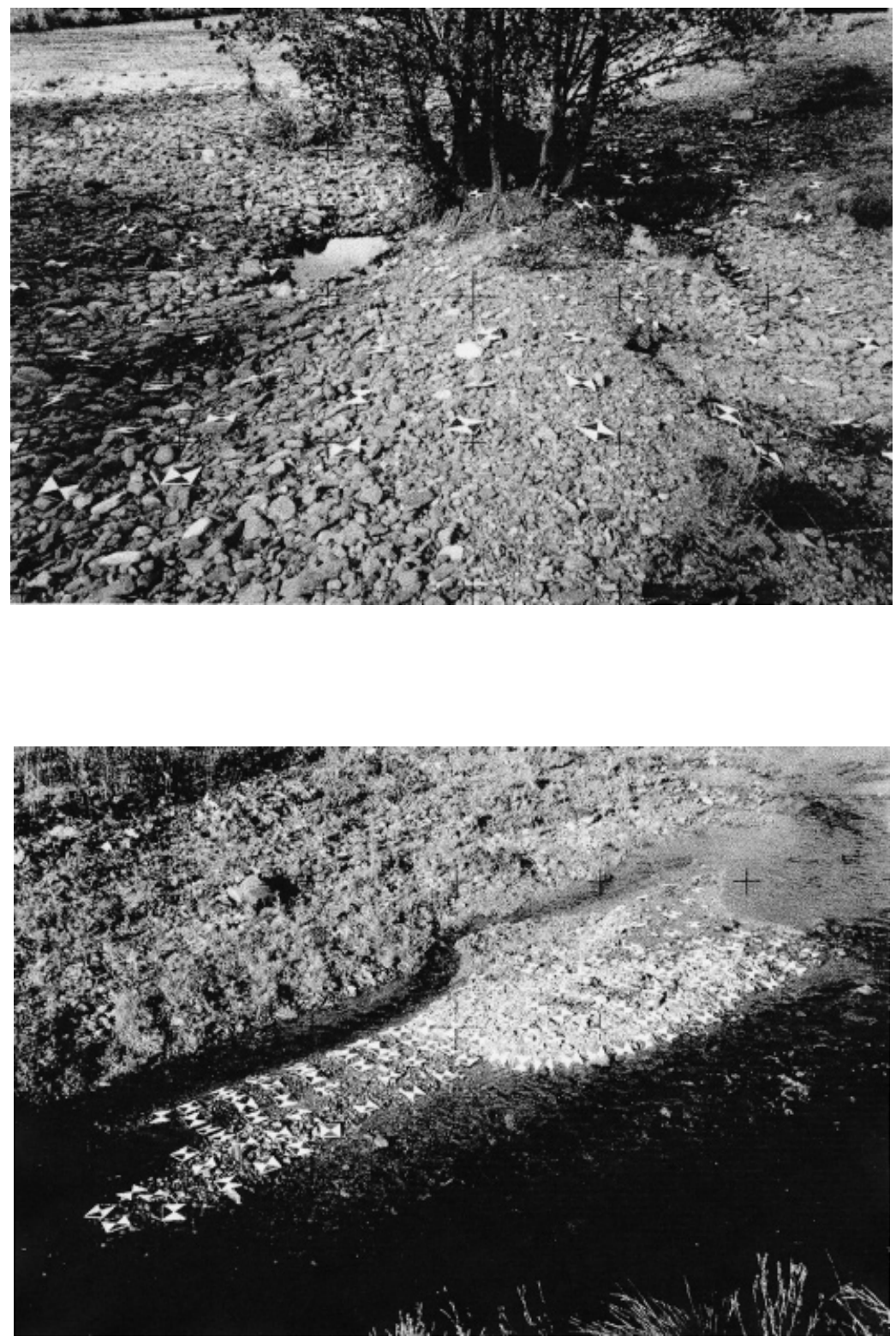

Figure 1. The four bar surfaces used to test the accuracy of the CDW photogrammetric survey technique: (a) the scour feature, flow is from left to right; (b) the mid-channel bar, flow is from top right to bottom left; (c) composite bar, flow is from top left to bottom right; (d) point bar, flow is from right to left 

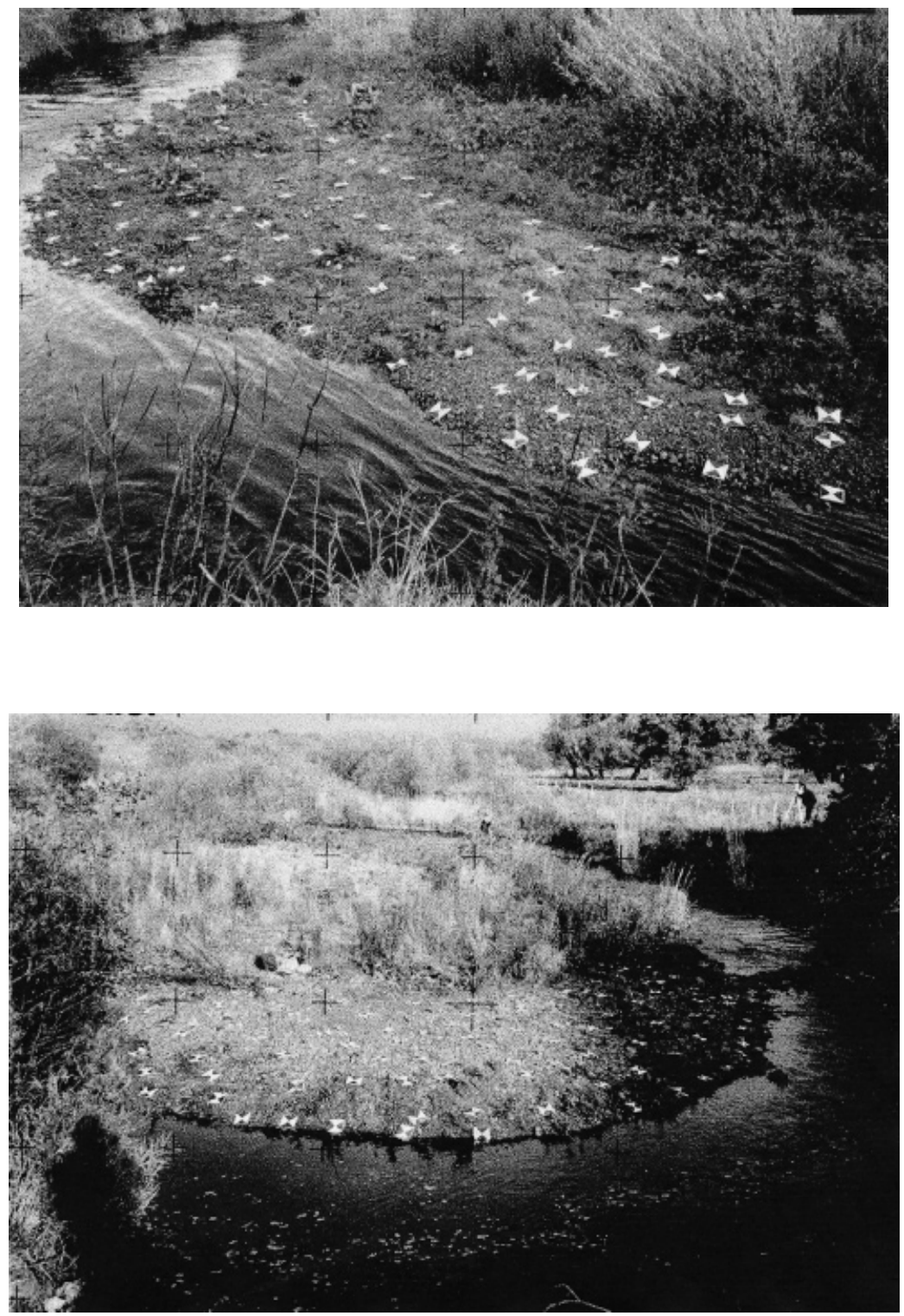

Figure 1 Continued. 


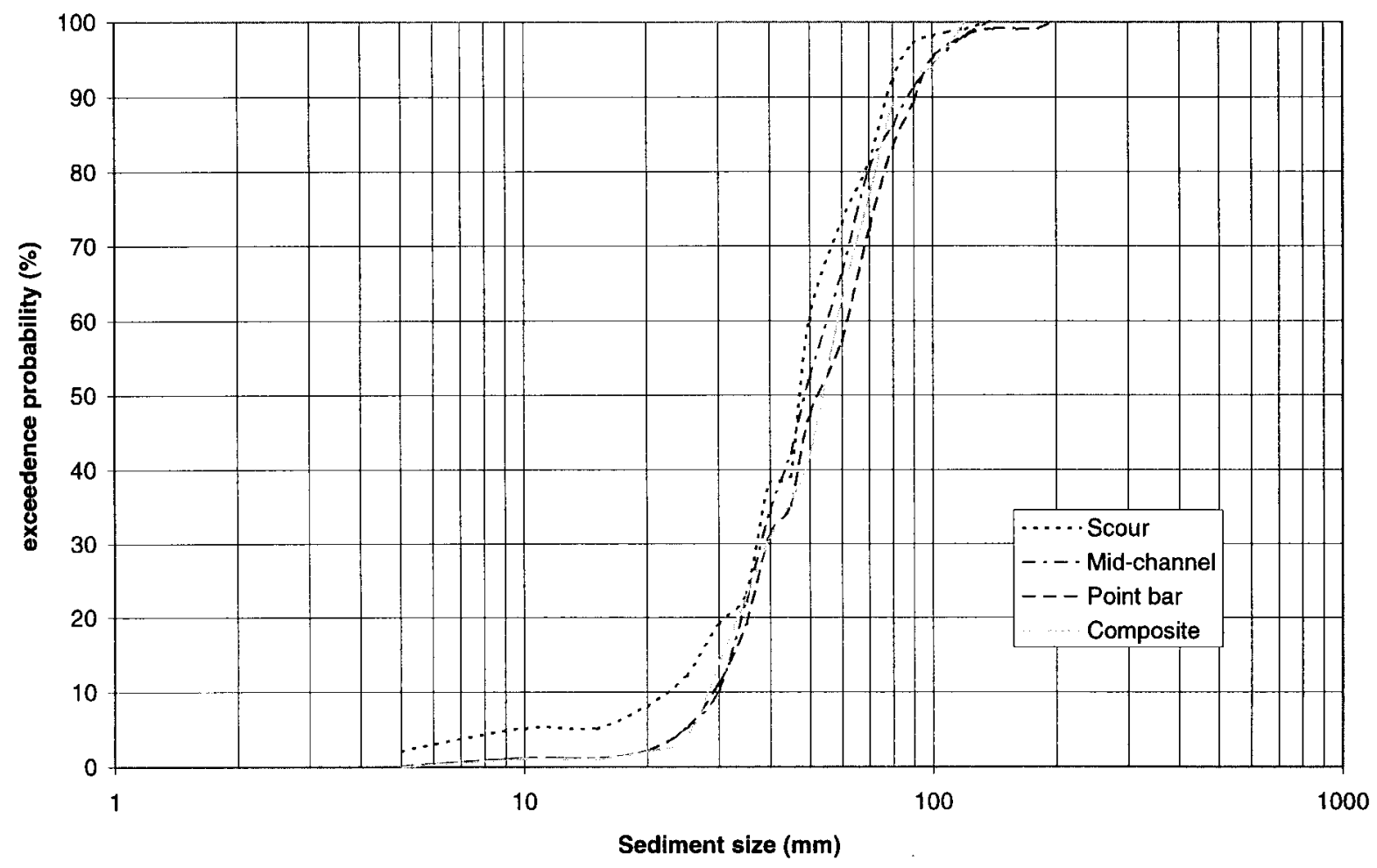

Figure 2. Surface sediment character of the four bar surfaces used to test the accuracy of the CDW photogrammetric survey technique

\section{PHOTOGRAMMETRIC SURVEY OF LOW RELIEF SURFACES}

The accuracy of the CDW photogrammetric survey was tested on two gravel-bed rivers in Northumberland, UK. Four low relief bar surfaces were selected, each one exhibiting a different topography or sedimentary setting (Figure 1); the site characteristics are described below.

1. Lateral bar scour features: a $10 \times 10 \mathrm{~m}$ area of a large lateral bar on the River Coquet at Holystone (NT 965024), exhibiting two distinct scour holes around vegetation (Figure 1). The bar surface consisted of coarse gravel $\left(D_{50}=48 \mathrm{~mm}\right.$, Figure 2$)$. Overall, the surface elevation varied by $1.173 \mathrm{~m}$ with the two scour holes forming negative features $1.5 \mathrm{~m}$ in diameter.

2. Mid-channel bar: a small $(2 \times 5 \mathrm{~m})$, very low relief feature on the Kingwater stream (NY 525637), a tributary of the River Irthing at Kellwood, exhibiting a raised upstream platform dropping abruptly onto a lower bar surface downstream (Figure 1). The surface of each platform varied by no more than $0.15 \mathrm{~m}$ and the surface material comprised coarse gravel $\left(D_{50}=49 \mathrm{~mm}\right.$, Figure 2$)$.

3. Composite lateral bar: a $3 \times 10 \mathrm{~m}$ bar on the Kingwater stream (NY 524635), comprising coarse gravel $\left(D_{50}\right.$ $=53 \mathrm{~mm}$, Figure 2 ) across its upper surface and finer gravel on the downstream lower elevation berm feature (Figure 1). The bar topography was regular, being highest close to the left bank of the river, falling away as a convex surface to the water's edge.

4. Point bar: the largest feature surveyed on the Kingwater stream $(6 \times 15 \mathrm{~m})$ (NY 524634). The bar exhibited a regular convex surface with a small chute channel towards the upstream edge of the inner bank (Figure 1); the maximum difference in relief was $0.579 \mathrm{~m}$ and the bar comprised coarse gravel $\left(D_{50}=53 \mathrm{~mm}\right.$, Figure 2$)$.

Each feature was surveyed using CDW photogrammetry based on an array of six oblique-angle photographs taken from a height of $3 \mathrm{~m}$ above the bar surface. Survey point density ranged from $4 \mathrm{~m}^{-2}$ over low relief surfaces to $12 \mathrm{~m}^{-2}$ across highly irregular terrain. The same area was then resurveyed using conventional 
Table I. Error evaluation statistics of the photogrammetric performance. The elevation difference represents the maximum relief over each bar surface; errors represent the difference between the tacheometric and the photogrammetric surfaces. The errors are given as the median $\left(\mathrm{q}^{2}\right)$, lower quartile $\left(\mathrm{q}^{1}\right)$ and upper quartile $\left(\mathrm{q}^{3}\right)$

\begin{tabular}{|c|c|c|c|c|c|c|c|c|}
\hline \multirow[t]{2}{*}{ Feature } & \multicolumn{2}{|c|}{ Sediment size } & \multirow{2}{*}{$\begin{array}{l}\text { Elevation } \\
\text { difference } \\
\quad(\mathrm{m})\end{array}$} & \multicolumn{5}{|c|}{ Errors in surface model } \\
\hline & $\begin{array}{c}D_{50} \\
(\mathrm{~mm})\end{array}$ & $\begin{array}{c}D_{84} \\
(\mathrm{~mm})\end{array}$ & & $\begin{array}{l}\text { Median } \\
\left(\mathrm{q}^{2}\right) \\
(\mathrm{m})\end{array}$ & $\underset{(\mathrm{m})}{\operatorname{Min}}$ & $\underset{(\mathrm{m})}{\operatorname{Max}}$ & $\begin{array}{c}\mathrm{q}^{1} \\
(\mathrm{~m})\end{array}$ & $\begin{array}{c}\mathrm{q}^{3} \\
(\mathrm{~m})\end{array}$ \\
\hline Lateral bar & 48 & 71 & $1 \cdot 173$ & $0 \cdot 026$ & $-0 \cdot 907$ & 1.960 & $-0 \cdot 073$ & $0 \cdot 233$ \\
\hline Mid-channel bar & 49 & 77 & $0 \cdot 315$ & -0.023 & $-0 \cdot 144$ & 0.065 & -0.034 & $-0 \cdot 011$ \\
\hline Composite bar & 53 & 74 & $0 \cdot 629$ & $-0 \cdot 041$ & $-0 \cdot 138$ & $0 \cdot 330$ & $-0 \cdot 057$ & $-0 \cdot 021$ \\
\hline Point bar & 53 & 82 & 0.579 & $-0 \cdot 011$ & $-0 \cdot 380$ & $0 \cdot 162$ & -0.038 & $0 \cdot 018$ \\
\hline
\end{tabular}

theodolite and EDM-based tacheometric techniques with survey points spaced at $0 \cdot 1-0 \cdot 3 \mathrm{~m}$ intervals. The Leica TC450 total station used in the survey had an angular resolution of 4 seconds, which represents a possible horizontal/vertical measurement error of $\pm 1.9 \mathrm{~mm}$ over $100 \mathrm{~m}$. Horizontal distance measurement was accurate to $\pm 5 \mathrm{~mm}$.

The irregularly spaced observations generated from the tacheometric and CDW techniques were interpolated using topogrid in ARC/INFO (ESRI, 1994). Topogrid is intended to produce hydrologically correct DTMs from irregularly spaced observations, and is based on Hutchinson's ANUDEM program (Hutchinson, 1989). The grid spacing of the interpolated DTMs was set at $0 \cdot 1$, following the recommendation of Lane et al. (1994), who suggest that accuracy in surface modelling is improved very little using grid densities greater than 100 points per square metre. Separate DTMs were created for the tacheometric survey measurements and the CDW measurements; the surfaces were then subtracted from one another to create a difference surface, which can be displayed, analysed and interrogated.

\section{PHOTOGRAMMETRIC ACCURACY}

The results of the photogrammetric survey of all four bar features indicate that the CDW technique accurately models the topographic surface within the limits defined by the grain roughness of each bar feature (Table I).

\section{Lateral bar scour feature}

Figure 3 represents the error surface (generated by subtracting the photogrammetric DTM from the conventional tacheometric survey DTM) draped over the topographic surface of the lateral bar scour feature on the River Coquet. Overall the errors are well within the limit defined by the surface sediment size $\left(D_{84}=71 \mathrm{~mm}\right)$. However, several features warrant discussion. The low ridge that extends along the right edge of the feature is very well defined by the conventional survey, but is not visible on the photogrammetric DTM because insufficient targets were used to define the feature. This emphasizes the need for systematic sampling, placing the photogrammetry targets carefully in order to define breaks of slope (a recommendation also made by Lane et al., 1994). Accuracy also declines away from the centre of the feature where target density is reduced. The scour features were modelled accurately, with average DTM differences within $0.026 \mathrm{~m}$ (Table I).

\section{Mid-channel bar}

The low relief mid-channel bar on the Kingwater stream was intensively sampled with targets spaced on average only $0.15 \mathrm{~m}$ apart (Figure 4 ). As a result, average differences between the photogrammetric DTM and the conventional tacheometric survey DTM were minimal (Table I). This accuracy is supported by the analysis of coincident data points across the bar surface which displayed almost identical elevations. Data point density was compared to the local topographic variation usin ARC/INFO (Figure 5). It is clear that point densities can be reduced considerably across regular low relief surfaces whilst maintaining the accuracy of the DTM to well within the limits defined by the surface sediment roughness $\left(D_{84}=77 \mathrm{~mm}\right)$. However, in order to maintain the accuracy of the survey, abrupt discontinuities, such as the drop from the upper to the lower bar surface, require a higher target density and careful target placement to ensure that slope changes are accurately incorporated into the DTM. The apparent discrepancy between the two DTMs towards the upper left of the bar (Figure 5) is a 


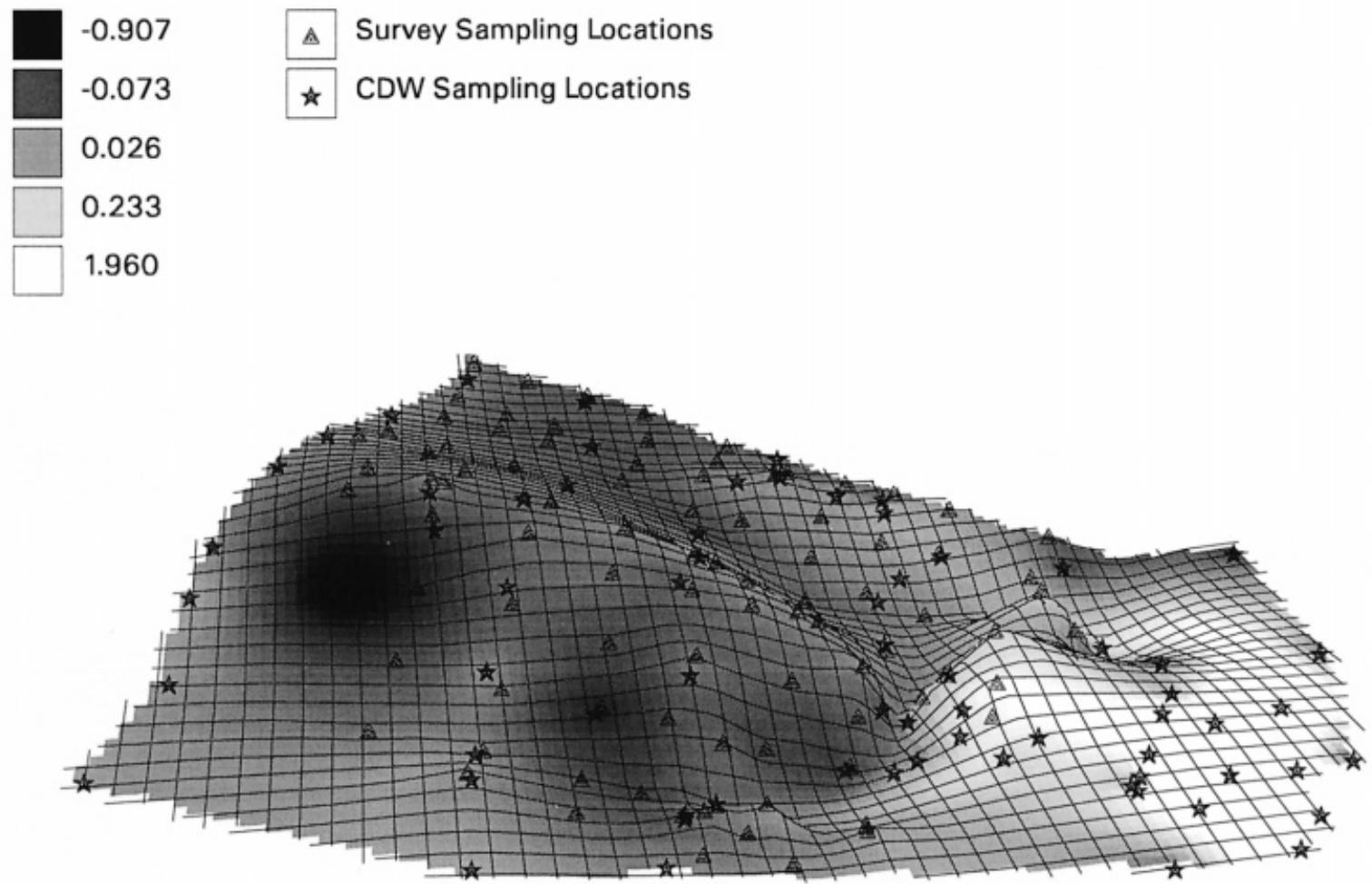

Figure 3. Errors associated with the photogrammetric mapping of a section of lateral bar on the River Coquet at Holystone (shading divisions represent minimum, quartiles and maximum errors in the CDW survey over a bar topography mesh)
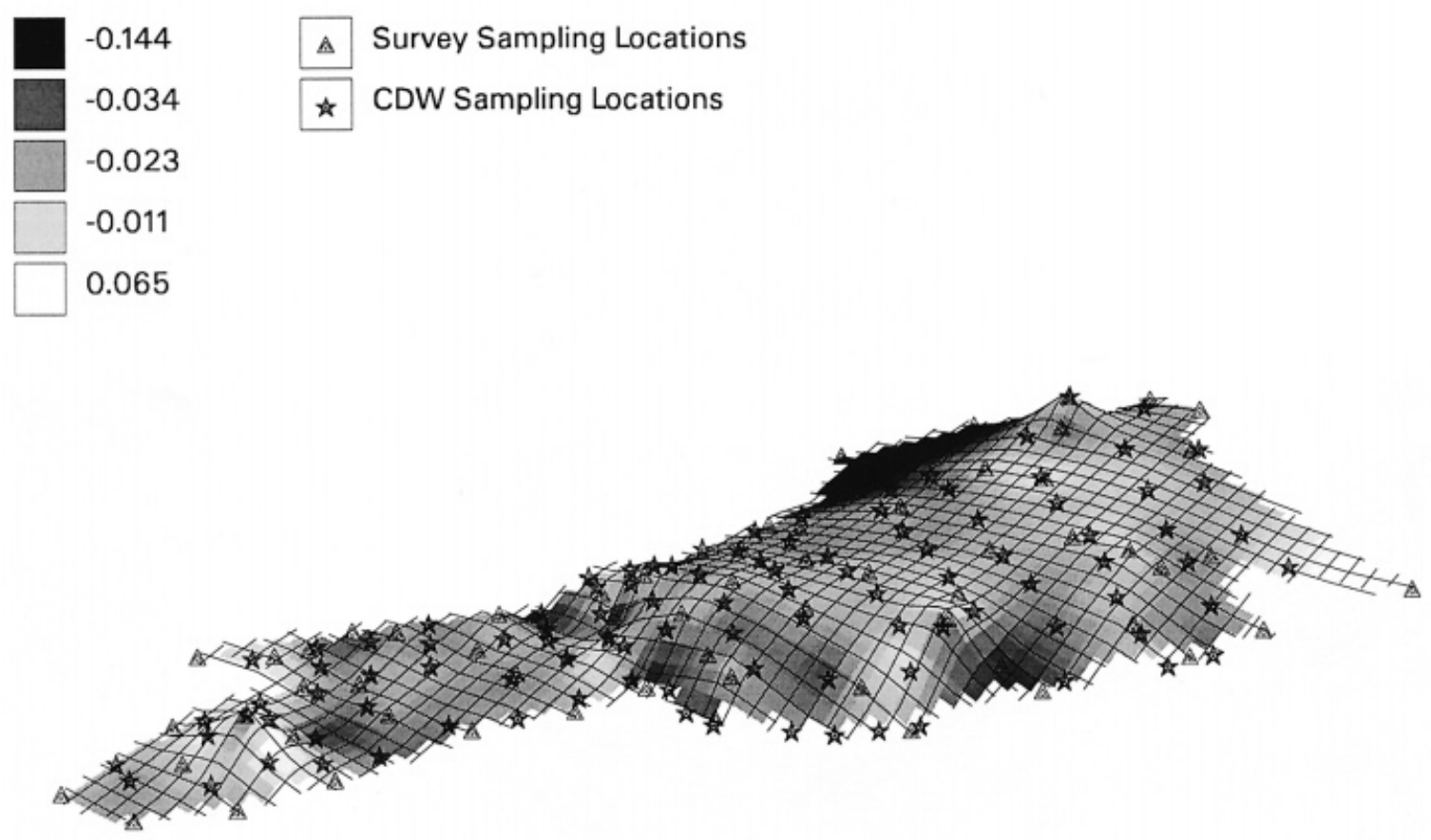

Figure 4. Errors associated with the photogrammetric mapping of a mid-channel bar on the Kingwater stream at Kellwood (shading divisions represent minimum, quartiles and maximum errors in the CDW survey over a bar topography mesh) 


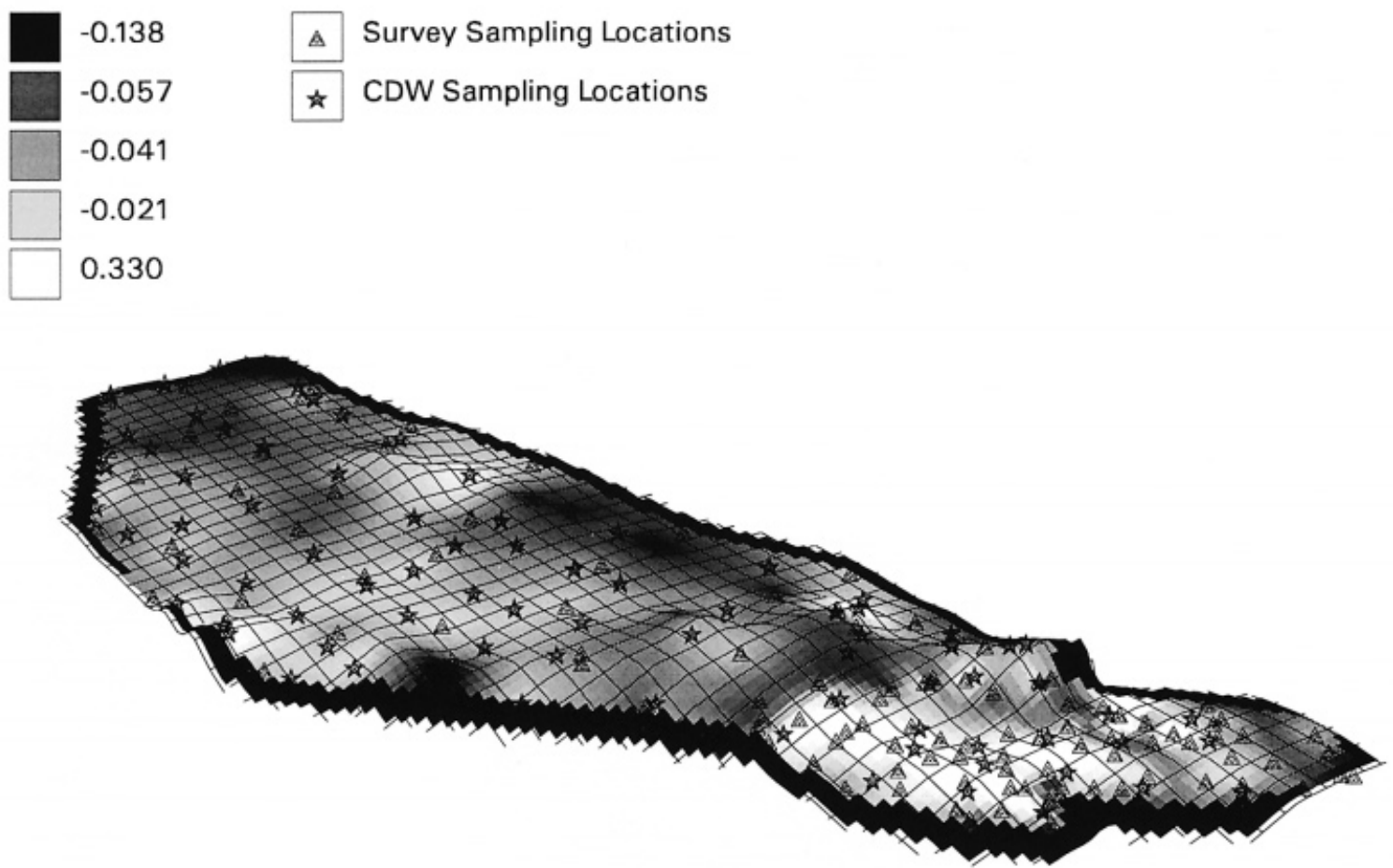

Figure 5. Target density and associated CDW survey errors as a function of the local surface irregularity across a mid-channel bar on the Kingwater stream at Kellwood (shading divisions represent minimum, quartiles and maximum of the CDW error surface over a local bar roughness mesh)

function of the limits of the two surveys. Here, the conventional tacheometric survey was used to define the boundary of the bar feature. Targets were not placed across this region of the bar and this has reduced the accuracy of the interpolation technique in this zone.

\section{Composite bar}

The composite bar surveyed on the Kingwater stream displayed a coarser main bar surface and a lower relief berm feature comprising a gravel matrix infilled with fines $\left(D_{84}=74 \mathrm{~mm}\right)$. Again, accuracy was within the limits defined by the size of the suface gravels (Figure 6); however, two points on the surface indicate that the photogrammetric DTM has not picked up surface depressions recorded by the conventional tacheometric survey. Closer inspection of these areas (Figure 7) indicates that the depressions have been contoured on the basis of single conventional survey points that are significantly lower than adjacent readings. It is likely that these represent gross survey errors as a result of the staff sinking into the surface of the bar or falling between clasts. Photogrammetry eliminates the possibility of these types of error occurring and produces a more accurate and objective set of survey data.

\section{Point bar}

The results of the photogrammetric survey of the point bar feature on the Kingwater stream indicate that the technique is also accurate for higher relief features comprising coarse sediment $\left(D_{84}=82 \mathrm{~mm}\right)$. This accuracy reflects the robustness of the CDW technique since the visibility of some survey targets was poor, particularly near the break of slope. The mean elevation difference between the two survey techniques was $\pm 0 \cdot 015 \mathrm{~m}$. Errors were increased close to the water's edge (Figure 8); again, this is a function of the spatial distribution of the data points. The tacheometric survey data most accurately track the edge of the water, whereas the photogrammetric points were recorded slightly in from the edge of the bar. Interpolation across the photogrammetric surface produced a lower elevation DTM in the zone lacking data points. Care must, therefore, always be taken to accurately define the boundary of a particular feature, particularly if the unit is to be resurveyed over time. 


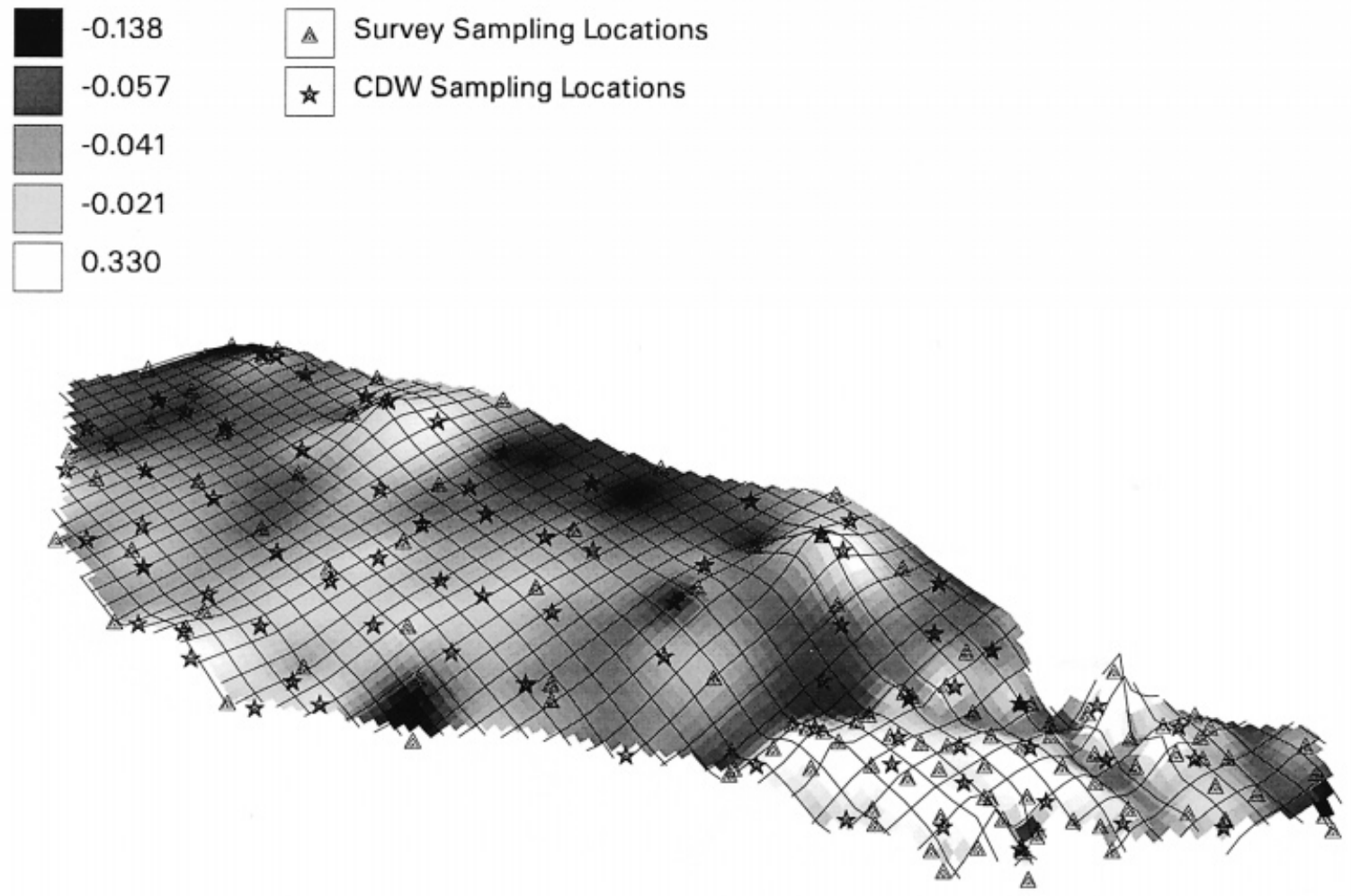

Figure 6. Errors associated with the photogrammetric mapping of a section of composite bar on the Kingwater stream at Kellwood (shading divisions represent minimum, quartiles and maximum errors in the CDW survey over a bar topography mesh)

Alternatively, where possible, data should be collected beyond the boundary of the unit being studied allowing the DTM to map more accurately the edge of the feature (Lane et al., 1994). The negative relief chute channel towards the top left of the bar (Figure 8) was mapped successfully by the photogrammetric survey. This was not picked up through the tacheometric survey due to insufficient density of data points across this part of the bar (spacing was every $0.35 \mathrm{~m}$ compared with an average of $0.25 \mathrm{~m}$ for the photogrammetric survey).

\section{DTM resolution}

The degree of resolution achievable across a topographic surface is a function of the survey point density (DeMers, 1997); sampling should also be more dense where there is greater local variability in the physical feature being sampled. The local standard deviation of the error surface for each feature effectively represents a measure of the local surface irregularity.

The local surface variability of any of the bars can be quantified by calculating a local standard deviation for a $0.7 \mathrm{~m} \times 0.7 \mathrm{~m}$ rectangle (or kernel). The ARC/INFO Grid module has a function named focalstd to accomplish this; in the output lattice, the raster at the centre of the kernel is given the standard deviation value of the 49 elevation measures within the kernel. These standard deviation values can then be mapped to give an indication of the locally changing variability of the surface; in flatter areas the local standard deviation will be closer to zero than in more undulating areas of the bar.

Using this method, the varying density of the sampling points was determined as follows: the number of sampling points in each $0 \cdot 1 \mathrm{~m} \times 0 \cdot 1 \mathrm{~m}$ grid cell was calculated, and the grid function focalsum used to total the number of points in a $0.7 \mathrm{~m} \times 0.7 \mathrm{~m}$ rectangle. A Gaussian kernel was employed to smooth the irregular local density estimates; weights $\left(w_{i j}\right)$ are computed for each cell in the kernel, related to this distance from the centre of middle cell $\left(d_{i j}\right)$ according to the formula: 

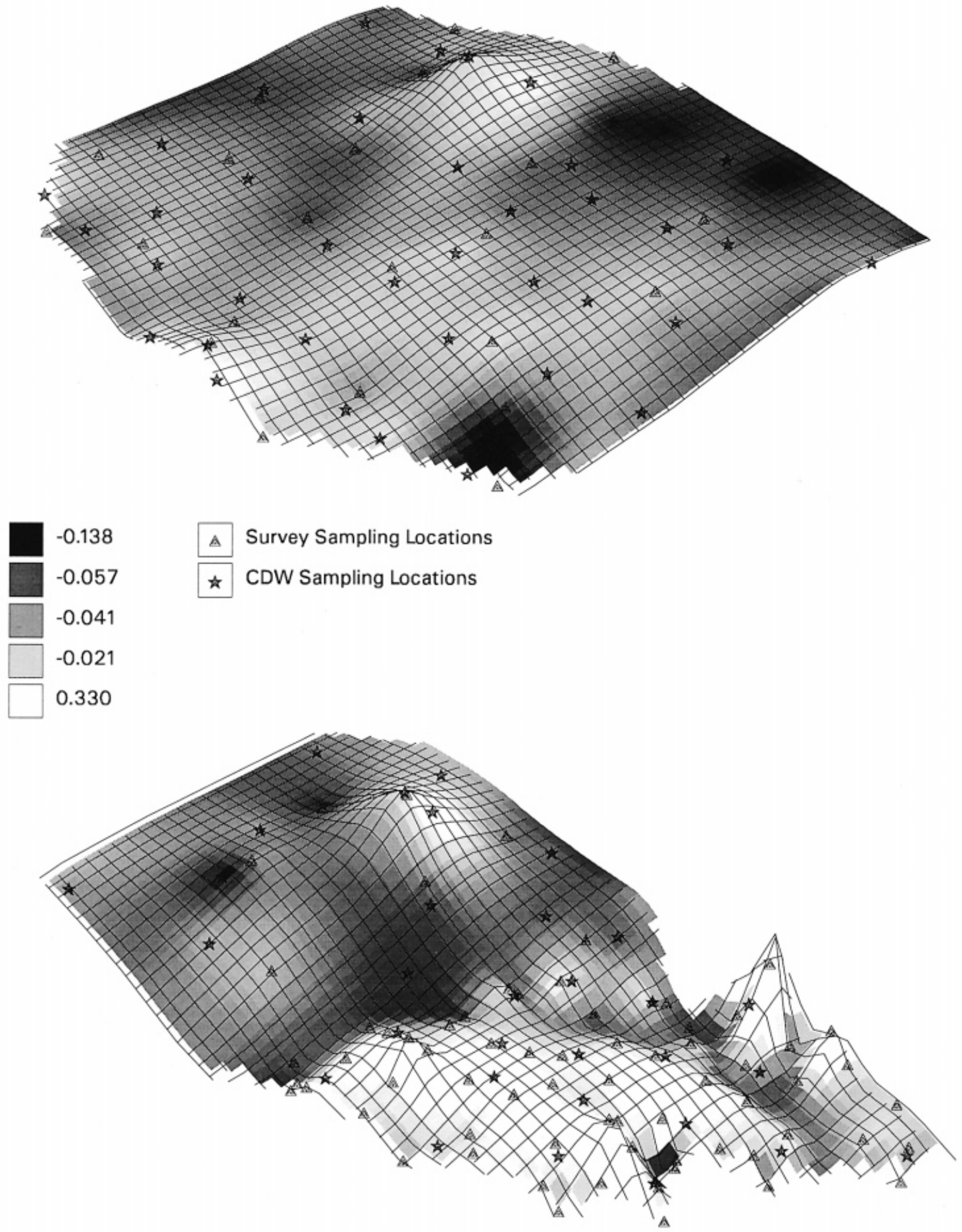

Figure 7. Magnified sections of the composite bar on the Kingwater stream illustrating the effect of gross survey error in the conventional survey DTM (shading divisions represent minimum, quartiles and maximum errors in the CDW survey over a bar topography mesh) 

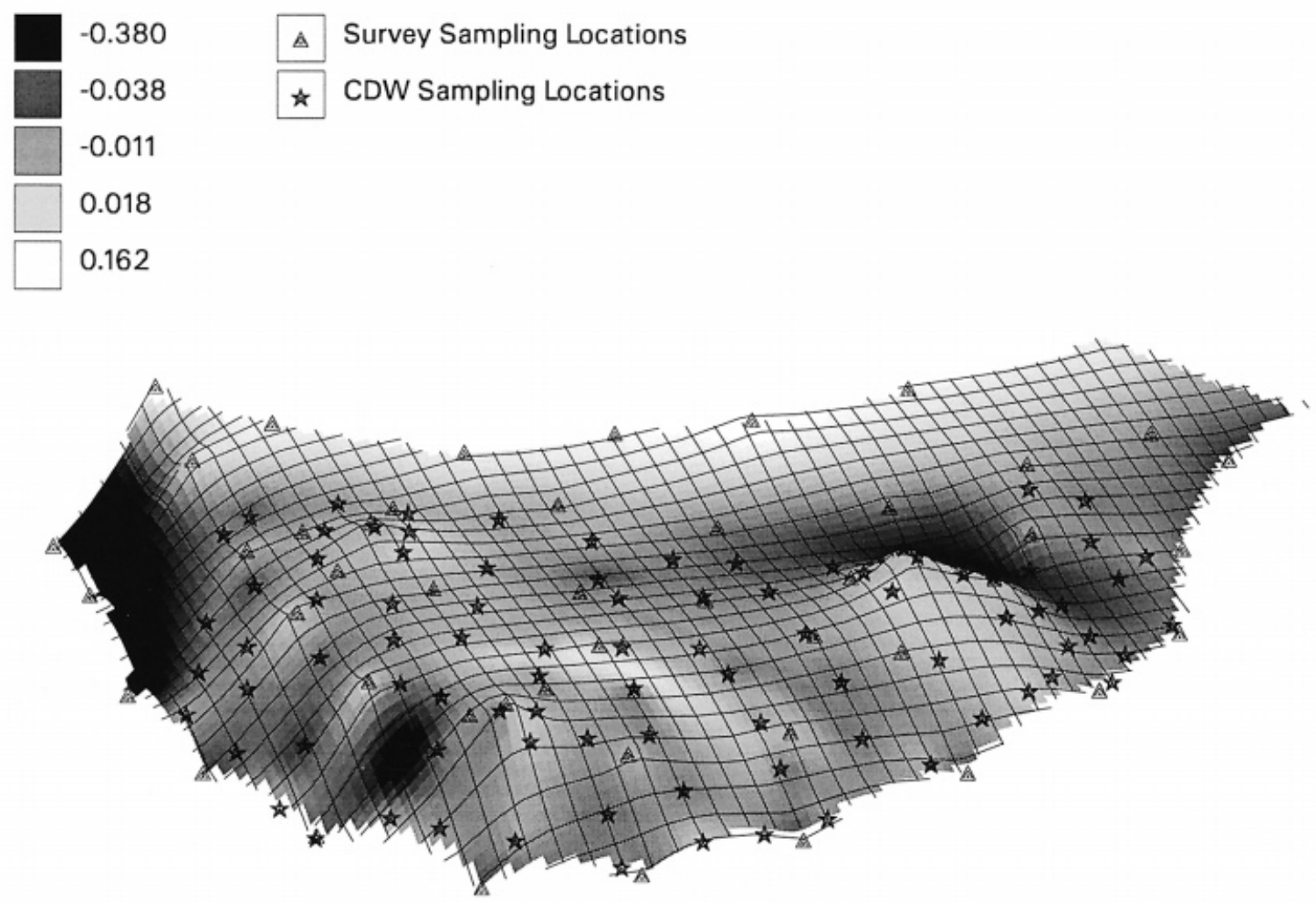

Figure 8. Errors associated with the photogrammetric mapping of a section of point bar on the Kingwater stream at Kellwood (shading divisions represent minimum, quartiles and maximum errors in the CDW survey over a bar topography mesh)

$$
w_{i j}=\mathrm{e}^{\left(-d_{i j} / h\right)^{2}}
$$

The smoothing parameter $h$ was set at 3 and the weights in the kernel were scaled so that their sum was unity.

The data indicate that there is a high degree of spatial correlation between the magnitude of the standard deviation surface and the associated errors in the photogrammetric surface. This can be attributed to gross surveying errors associated with both the photogrammetric survey (target position in relation to the irregular sediment surface) and conventional tacheometric survey (staff position in relation to the irregular sediment surface). Figure 9 details the results of anlysing the CDW photogrammetric survey error associated with increasing topographic roughness; the three zones represent desired accuracy limits of $<0 \cdot 1 \mathrm{~m}, 0 \cdot 1-0 \cdot 3 \mathrm{~m}$ and $>0.3 \mathrm{~m}$. It is anticipated that this approach will aid the determination of suitable target density in future photogrammetric studies provided that a priori decisions are made concerning desired survey accuracy and the irregularity of the feature being surveyed.

\section{APPLICATIONS: TOWARDS RAPID AND HIGH-RESOLUTION ASSESSMENT OF FLUVIAL EROSION, TRANSPORT AND DEPOSITION}

Geomorphologists and river engineers have long sought to quantify rates of erosion, transport and deposition of sediment in fluvial systems. Here, attention is drawn to the potential application of CDW in furthering highresolution assessment of sediment transfers in the context of (i) river bank erosion and (ii) fluvial sediment budgeting at reach and bar-form scales. 


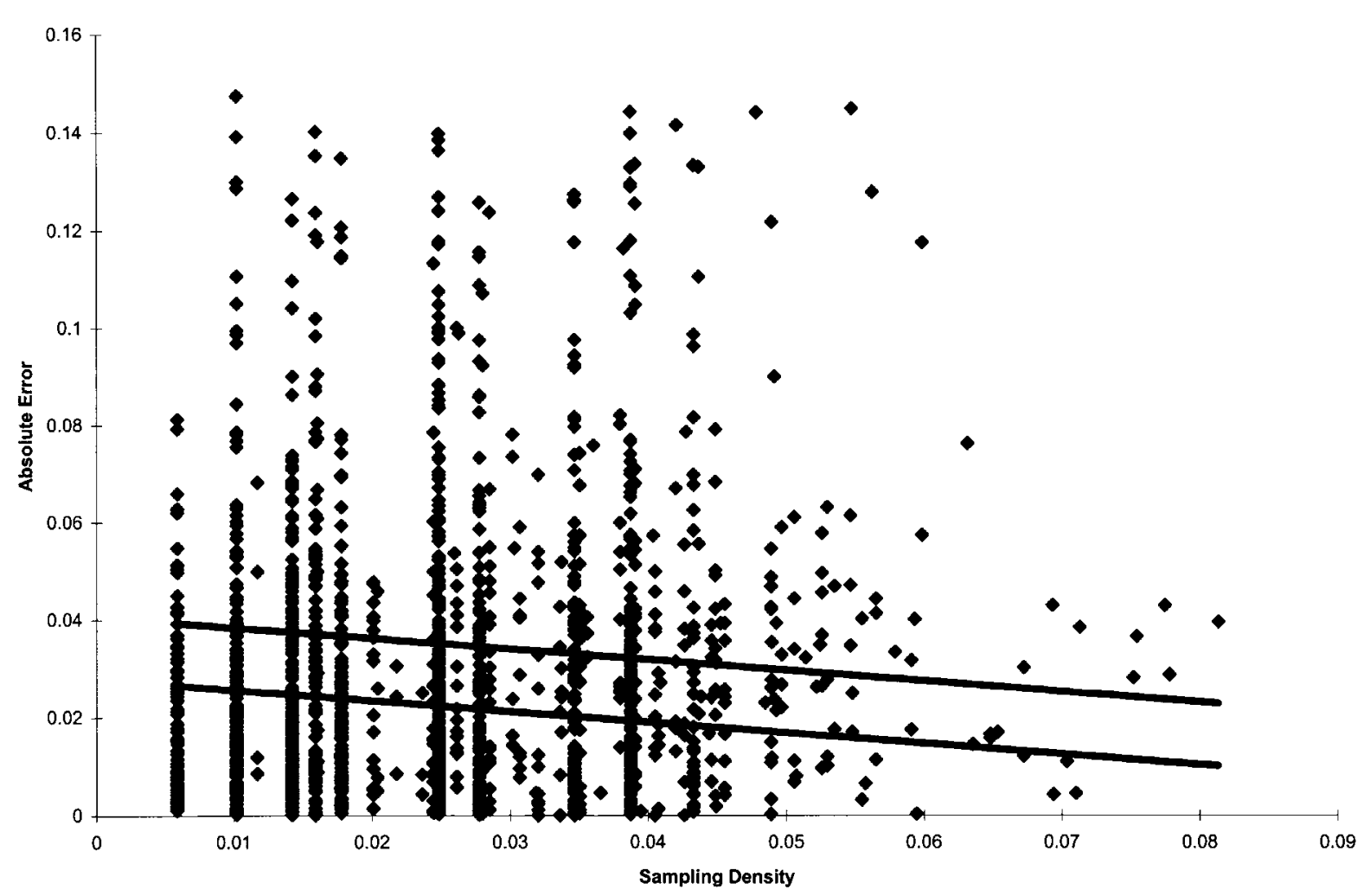

Figure 9. Expected error limits associated with target density in relation to topographic irregularity

\section{River bank erosion}

Investigations of river bank erosion have been conducted on temporal scales ranging from real-time monitoring (using erosion pins, cf. Lawler et al., 1992) to decadal-century scale analyses facilitated by cartographic and documentary sources (e.g. Hooke and Redmond, 1989, 1992). At intermediate annual or subannual timescales, bank erosion rates have typically been monitored via repeat survey of bank profiles spaced at intervals throughout the study reach (Barker et al., 1997). Recent work has demonstrated, however, that repeat photogrammetric surveys offer a high-resolution means of avoiding the potential errors derived from extrapolating between profiles (Barker et al., 1997). CDW appears to constitute an equally effective and rapid means of conducting such analyses.

\section{Fluvial sediment budgeting}

Quantifying rates of river bank erosion may constitute an important element of fluvial sediment budget analyses that encompass reach-scale development of active channel and floodplain systems. In gravel-bed rivers, however, assessment of sediment transfers within the active channel zone has been inhibited by the inherent difficulties in measuring bedload transport, as well as by the limitations of sediment transport formulae. In recognition of these problems, geomorphologists have increasingly turned to the analysis of morphological changes in channel and bar planforms (e.g. Goff and Ashmore, 1994; Martin and Church, 1995). Investigations of morphological change commonly employ repeat surveys of bed and bar elevation (e.g. via cross-profiles or bathymetry) and/or planform adjustments, typically focusing on spatial scales ranging from single meander bends to extended river reaches of several kilometres (e.g. Martin and Church, 1995; Macklin et $a l .$, in press).

Typical components of a sediment budget based on morphological parameters are illustrated in Figure 10. Here the reach is mapped at the resolution of discrete morphological units (e.g. bar platform, channel) and partitioned into subreaches defined by two or more monumented cross-profiles. Volumetric estimates of net 


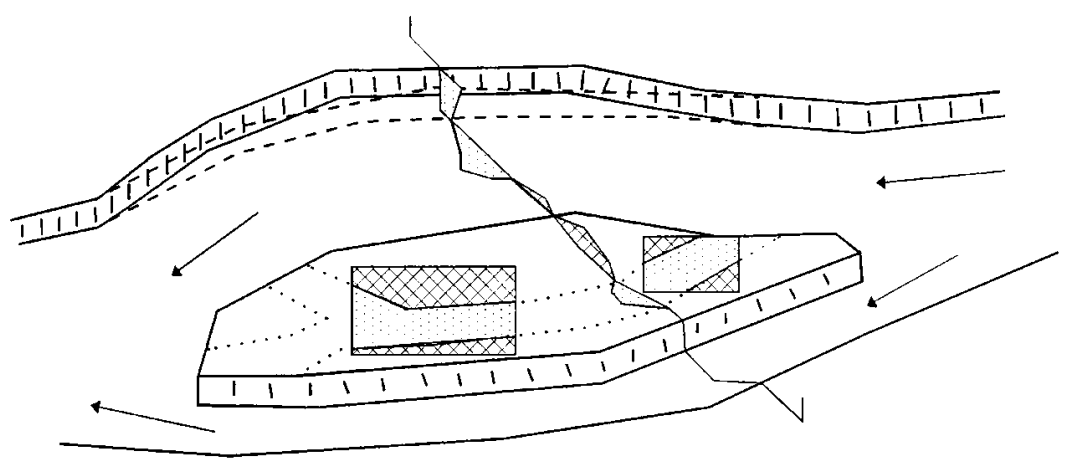

Figure 10. Improved sediment budgeting technique incorporating CDW photogrammetry (stippled areas represent erosion and hatched areas represent deposition)

sediment gain/loss for each specific morphological unit may be obtained by synthesizing elevation changes (where traversed by repeat cross-profiles) with planform changes (derived from repeat mapping). Volumetric change for all morphological units may then be summed to yield a net sediment gain/loss $\left(\mathrm{m}^{3}\right)$ for the subreach. A potentially significant source of error inherent to this technique lies in the need to extrapolate vertical changes measured along cross-profiles (calculated as net gain/loss per $\mathrm{m}^{3}$ ) uniformly across the morphological unit upstream and downstream of the transect. For morphological unit surfaces lying above the water surface, however, CDW photogrammetry offers a means of rapidly assessing spatial variation in erosion and deposition occurring between cross-profiles. These data may then be used to calibrate estimates of vertical change with morphological units, thereby enhancing the resolution and reliability of sediment budgeting.

\section{CONCLUSIONS}

- CDW photogrammetry provides a technique for the rapid collection of objective data, based on break of slope survey.

- Accuracy achieved in mapping low relief fluvial morphological units of the order of $10-100 \mathrm{~m}^{2}$ is well within the range defined by the surface grain size $\left(D_{84}\right)$.

- Survey area could be increased by merging adjacent sets of oblique photographs during the processing stage or increasing the height at which the photographs are taken by use of an extendable pole with a camera attachment.

- Survey accuracy increases with target density and minimum levels are suggested as a function of topographic variation.

- Geomorphological boundaries should be carefully defined to allow for accurate resurvey. This will minimize the interpolation effects that can occur when survey areas do not overlap perfectly.

- The photographs remain as a permanent record of the topographic surface surveyed, allowing anomalous data points to be checked. It will also permit the reanalysis of the feature to incorporate new data points where necessary.

- Conventional tacheometric land surveying using a theodolite and staff is prone to gross errors as a result of staff placement. The use of photogrammetry, employing targets, produces a surface that is not prone to these types of error.

\section{ACKNOWLEDGEMENTS}

The authors would like to thank Ms Jacqui Cotton for assistance in the field. The purchase of the RolleiMetric camera and CDW software was funded by HEFCE income to the University of Northumbria at Newcastle. 


\section{REFERENCES}

Barker, R., Dixon, L. and Hooke, J. 1997. 'Use of terrestrial photogrammetry for monitoring and measuring bank erosion', Earth Surface Processes and Landforms, 22, 1217-1227.

DeMers, M. N. 1997. Fundamentals of Geographic Information Systems, Wiley, Chichester.

ESRI. 1994. Arc/INFO User Manual, ESRI, Redlands, California.

Goff, J. and Ashmore, P. E. 1994. 'Gravel transfer rates and morphological changes in braided Sunwapta River, Alberta, Canada', Earth Surface Processes and Landforms, 19, 195-212.

Hooke, J. M. and Redmond, C. E. 1989. 'River channel changes in England and Wales', Journal of the Institute of Water and Environmental Management, 3, 328-335.

Hooke, J. M. and Redmond, C. E. 1992. 'Causes and nature of river planform change', in Billi, P., Hey, R. D., Thorne, C. R. and Tacconi, P. (Eds), Dynamics of Gravel-bed Rivers, Wiley, Chichester, 557-571.

Hutchinson, M. F. 1989. 'A new procedure for gridding elevation and stream line data with the automatic removal of spurious pits', Journal of Hydrology, 106, 211-232.

Kirby, R. B. 1991. 'Measurement of surface roughness in desert terrain by close range photogrammetry', Photogrammetric Record, 13, $855-875$.

Lane, S. N., Richards, K. S. and Chandler, J. H. 1993. 'Developments in photogrammetry: the geomorphological potential'. Progress in Physical geography, 17(3), 306-328.

Lane, S. N., Chandler, J. H. and Richards, K. S. 1994. 'Developments in monitoring and modelling small-scale river bed topography', Earth Surface Processes and Landforms, 19, 349-368.

Lawler, D. M. 1993. 'Measurement of river bank erosion and lateral channel change: a review', Earth Surface Processes and Landforms, 18(9), 777-821.

Macklin, M. G., Passmore, D. G. and Newson, M. D. (in press). 'Controls of short and long term river instability: processes and patterns in gravel-bed rivers, the Tyne basin, northern England', Proceedings of the 4th International Gravel Bed Rivers Conference, Washington State.

Martin, Y. and Church, M. 1995. 'Bed-material transport estimated from channel surveys: Vedder River, British Columbia', Earth Surface Processes and Landforms, 20, 347-361.

Petrie, G. and Kennie, T. J. M. 1987. 'Terrain modelling in surveying and civil engineering', Computer Aided Design, 19, $171-187$.

Wicken, E. and Barton, N. R. 1971. 'The application of photogrammetry to the stability of excavated rock slopes', Photogrammetric Record, 7, 46-54. 